\section{Rabies - ghastly deaths are vaccine preventable}

To the Editor: The rabies virus can be likened to a stealthy demon that infects and kills its host in a horrific manner. It is deadlier than Ebola or HIV, yet its prevalence and lethality are often unpublicised. Human rabies accounts for a substantial proportion of deaths worldwide, especially affecting children in settings with limited access to healthcare or lack of awareness. ${ }^{[1,2]}$

The majority of human rabies is transmitted by dog bites, and the One Health approach focusing on prevention of rabies in animals, primarily by vaccination, will therefore have a direct effect on preventing human rabies. ${ }^{[3]}$ Despite this, rabies elimination is not prioritised and knowledge on rabies prevention among the general public and healthcare workers is often inadequate.

In 2017 there were six laboratory-confirmed cases of human rabies in South Africa (SA), and in 2018 there have been three confirmed cases, one probable case and two suspected cases to date. ${ }^{[4,5]}$ In KwaZulu-Natal and Eastern Cape provinces, there has been a recent surge in rabies with deaths in children following dog and cat bites. The tragic loss of these young lives could have been entirely preventable, since effective post-exposure prophylaxis for rabies is available in the form of wound care, rabies immunoglobulin and rabies vaccine. ${ }^{[6]}$ Rabies immunoglobulin in addition to rabies vaccine is indicated for category 3 exposures, which include bites or scratches that penetrate the skin, licking of mucous membranes or broken skin, and direct contact with bats (Table 1). Although the supply of human rabies immunoglobulin has been limited owing to cost, equine rabies immunoglobulin is available, which is effective and reported as safe with a low risk of anaphylaxis. ${ }^{[8]}$

Education in rural and urban communities by engaging with community leaders, chiefs, farmers, pet owners and schools on rabies prevention will create awareness among the public. ${ }^{[9]}$ Annual vaccination of dogs and cats provided free of charge proved to be successful campaigns in reducing the burden of rabies. ${ }^{[10]}$ These efforts must be sustained in order to achieve elimination and prevent resurgence. ${ }^{[1]}$ The primary school education curriculum should include basic content to educate young children on the dangers of an animal bite and encourage them to seek help. Healthcare centres should display posters and provide information on rabies, and all healthcare workers must be adequately trained on how to manage a patient with potential rabies exposure from primary healthcare level where patients often present. Improving access to safe, effective and inexpensive post-exposure prophylaxis must be prioritised.

SA commemorated Human Rights Day on 21 March. Children are among the most vulnerable in our population and have a constitutional right to be protected. Against this backdrop exists a rabies outbreak with loss of lives. It is therefore imperative for us as healthcare workers to promote education on rabies prevention and provide effective healthcare. Working with veterinarians to vaccinate animals and with community leaders to educate the public will help in advancing the goal of human rabies elimination by $2030 .{ }^{[12]}$

\section{Aabida Khan}

Department of Virology, School of Laboratory Medicine and Medical Sciences, Nelson R Mandela School of Medicine, University of KwaZulu-Natal, Durban, South Africa; and National Health Laboratory Service, Inkosi Albert Luthuli Central Hospital, Durban, South Africa

aabida.khan1@gmail.com

1. Fooks AR, Banyard AC, Horton DL, Johnson N, McElhinney LM, Jackson AC. Current status of rabies and prospects for elimination. Lancet 2014;384(9951):1389-1399. https://doi.org/10.1016/S01406736(13)62707-5

2. Hampson K, Coudeville L, Lembo T, et al. Estimating the global burden of endemic canine rabies. PLoS Negl Trop Dis 2015;9(4):e0003709. https://doi.org/10.1371/journal.pntd.0003709

3. Durrheim DN, Blumberg L. Rabies - what is necessary to achieve 'zero by 30'? Trans R Soc Trop Med Hyg 2017;111(7):285-286. https://doi.org/10.1093/trstmh/trx055

4. National Institute for Communicable Diseases. Rabies in South Africa. NICD Communicable Diseases National Institute for Communicable Diseases. Rabies in South Africa. NICD Communicable Diseas s Communique February 2018;17(2). http://Www.nicd.ac.za/index.php/publications/nicd-nhls-
communicable-diseases-communique/ (accessed 10 April 2018).

cons

ind on rabies in South Africa. NICD Communicable Diseases Communique March 2018;17(3). http://www.nicd.ac.za/index.php/ publications/nicd-nhls-communicable-diseases-communique/ (accessed 10 April 2018).

6. National Department of Health, South Africa. Affordable Medicines: Hospital Level Paediatric Standard Treatment Guidelines and Essential Medicine List, 2017 edition. http://www.health.gov.za/ index.php/standard-treatment-guidelines-and-essential-medicines-list (accessed 10 April 2018)

7. National Department of Health, South Africa. Affordable Medicines: Primary Health Care Leve Standard Treatment Guidelines and Essential Medicine List for South Africa, 2014 edition. http://www. health.gov.za/index.php/standard-treatment-guidelines-and-essential-medicines-list/category/285phc (accessed 10 April 2018).

8. National Department of Health, South Africa. Notice: Recommended therapeutic alternative for human rabies immunoglobulin. 2016. http://www.nicd.ac.za/assets/files/Circular_Therapeutic\%20 alternative\%20for\%20HRIG_07June2016.pdf (accessed 10 April 2018).

9. Hasanov E, Zeynalova S, Geleishvili M, et al. Assessing the impact of public education on a preventable zoonotic disease: Rabies. Epidemiol Infect 2018;146(2):227-235. https://doi.org/10.1017/
poratic preventable zoonotic

10. Shwiff SA, Hatch B, Anderson A, et al. Towards canine rabies elimination in KwaZulu-Natal, South Africa: Assessment of health economic data. Transbound Emerg Dis 2016;63(4):408-415. https://doi. org $/ 10.1111 /$ tbed.1228

11. Dürr S, Fahrion AS, Knopf L, Taylor LH. Editorial: Towards elimination of dog mediated human rabies. Front Vet Sci 2017;4(142). https://doi.org/10.3389/fvets.2017.00142

12. World Health Organization. New global framework to eliminate rabies 2015. http://www.who.int/ mediacentre/news/releases/2015/eliminate-rabies/en/ (accessed 10 April 2018).

S Afr Med J 2018;108(5):359. DOI:10.7196/SAMJ.2018.v108i5.13302

Table 1. Categories of exposure and management for suspected rabies exposure ${ }^{[7]}$

\begin{tabular}{lll}
\hline Category & Type of exposure & Management \\
\hline 1 & Touching or feeding of animal & No treatment if history is reliable \\
& Licking of intact skin & If history not reliable, treat as category 2 \\
& Nibbling of uncovered skin & Wound management \\
& Superficial scratch without bleeding & Administer full course vaccine. Only stop if animal \\
& & tested negative for rabies or is still healthy after 10 days' \\
& & observation \\
& & Do not give immunoglobulin, except in \\
& immunocompromised patients \\
& Bites/scratches that penetrate the skin and with any visible blood & Wound management \\
Direct contact with a bat & Administer full course vaccine. Only stop if animal & tested negative for rabies or is still healthy after 10 days' \\
& observation \\
& Administer rabies immunoglobulin \\
& Administer tetanus vaccine
\end{tabular}

